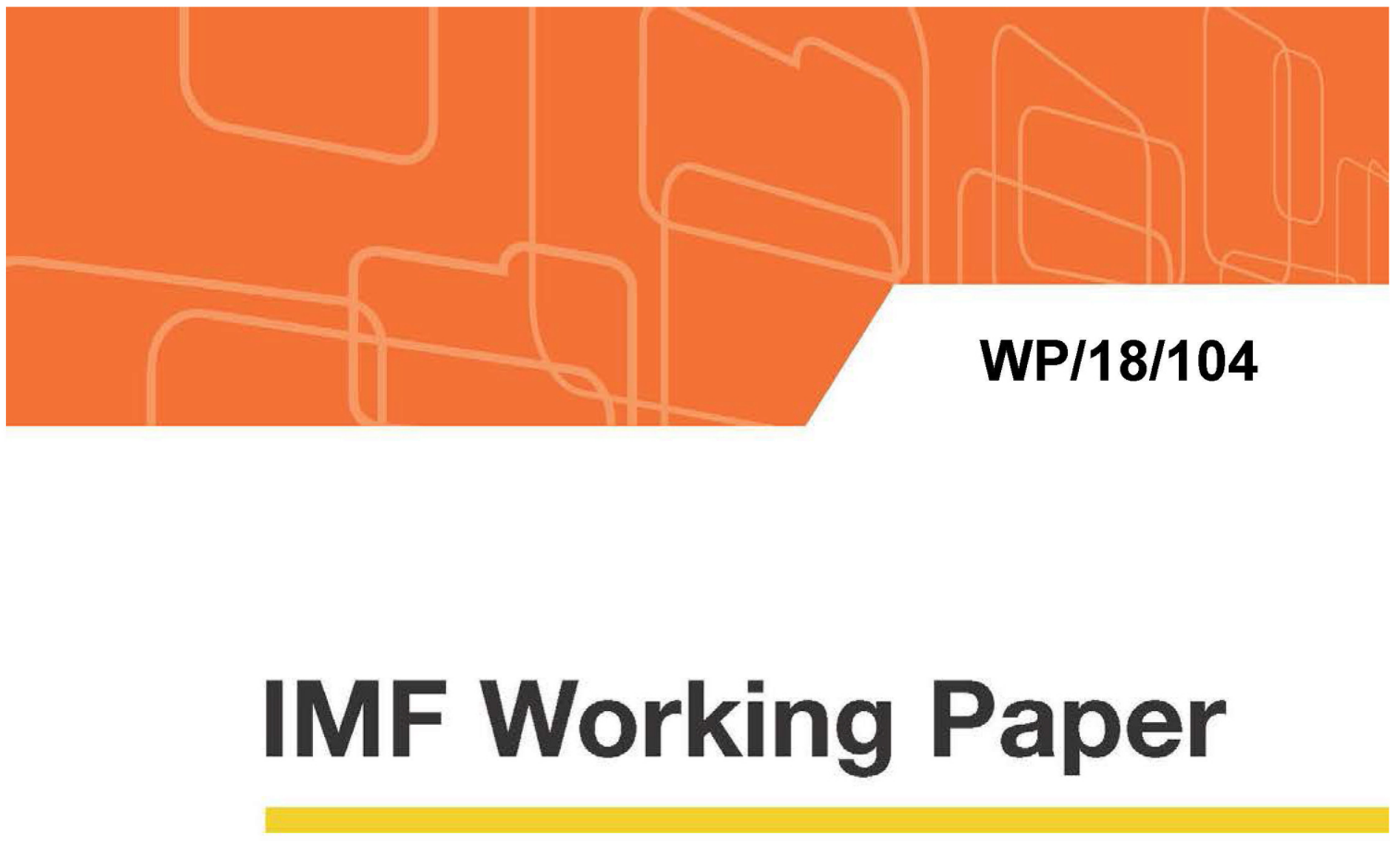

\title{
Debt Seniority and Sovereign Debt Crises
}

by Anil Ari, Giancarlo Corsetti \& Luca Dedola

IMF Working Papers describe research in progress by the author(s) and are published to elicit comments and to encourage debate. The views expressed in IMF Working Papers are those of the author(s) and do not necessarily represent the views of the IMF, its Executive Board, or IMF management. 


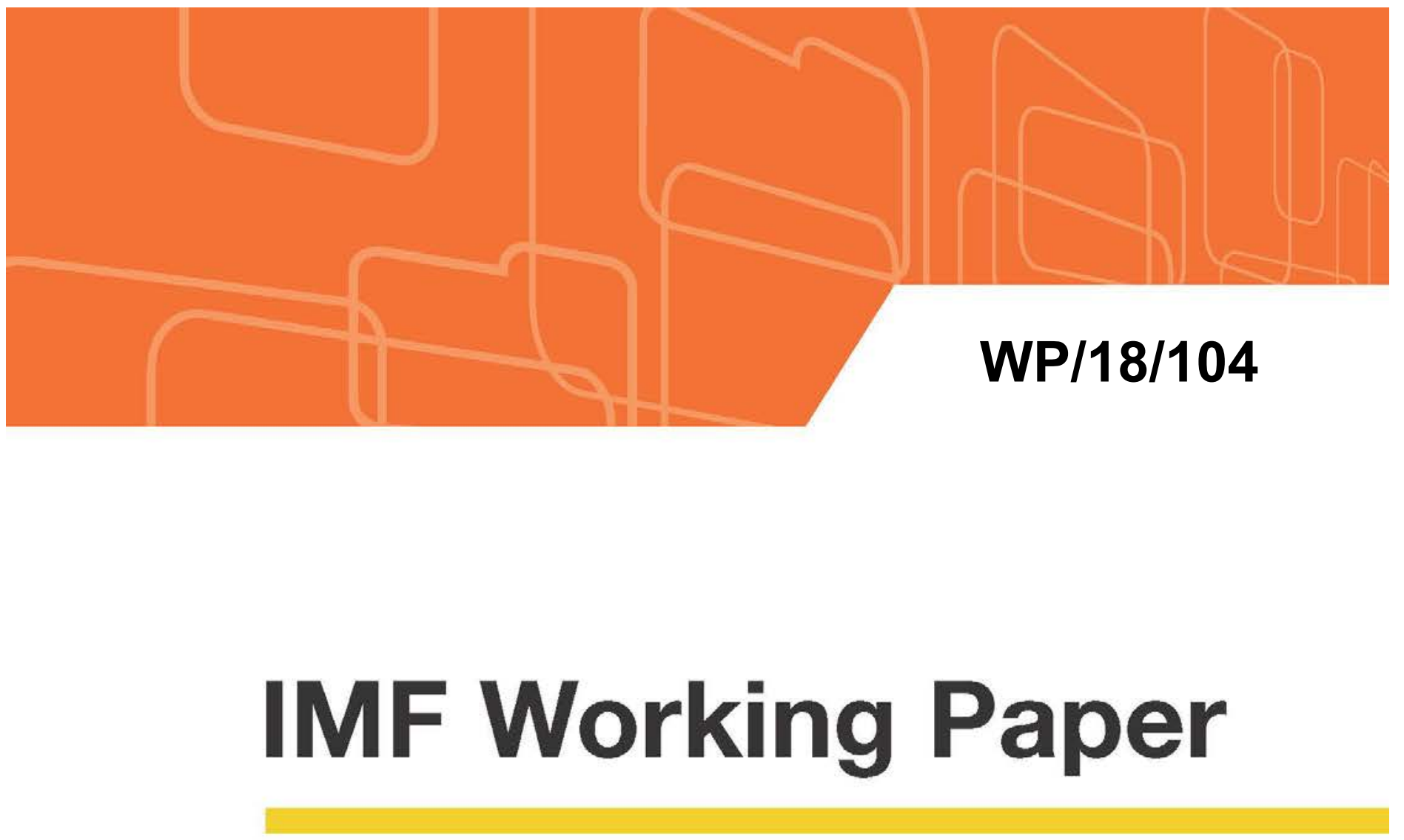

\section{Debt Seniority and Sovereign Debt Crises}

by Anil Ari, Giancarlo Corsetti \& Luca Dedola

IMF Working Papers describe research in progress by the author(s) and are published to elicit comments and to encourage debate. The views expressed in IMF Working Papers are those of the author(s) and do not necessarily represent the views of the IMF, its Executive Board, or IMF management.

I N T E R N A T I O N A L M O N E T A R Y F U N D 


\title{
IMF Working Paper
}

Research Department

Debt Seniority and Sovereign Debt Crises ${ }^{1}$

Prepared by Anil Ari, Giancarlo Corsetti \& Luca Dedola

Authorized for distribution by Maria Soledad Martinez Peria

May 2018

\section{IMF Working Papers describe research in progress by the author(s) and are published to elicit comments and to encourage debate. The views expressed in IMF Working Papers are those of the author(s) and do not necessarily represent the views of the IMF, its Executive Board, or IMF management.}

\begin{abstract}
Is the seniority structure of sovereign debt neutral for a government's decision between defaulting and raising surpluses? In this paper, we address this question using a model of debt crises where a discretionary government endogenously chooses distortionary taxation and whether to apply an optimal haircut to bondholders. We show that when the size of senior tranches is small, a version of the Modigliani-Miller theorem holds: tranching just redistributes government revenues from junior to senior bondholders, while taxes and government borrowing costs remain unchanged. However, as senior tranches become sufficiently large, default costs on senior debt transpire into a stronger commitment to repay not only the senior tranche, but also the junior one. We show that there is a lower threshold for senior bonds above which tranching can eliminate default on both junior and senior debt, and an upper threshold beyond which the government defaults also on senior debt.
\end{abstract}

JEL Classification Numbers: F34, G12, H63

Keywords: Debt crises; Sovereign default; Seniority; Eurobonds; Multiple equilibria; Selffulfilling expectations.

Author’s E-Mail Address: aari@imf.org,gc422@,cam.ac.uk, luca.dedola@ecb.int

\footnotetext{
${ }^{1}$ We thank, without implicating, Leonardo Martinez, Divya Kirti, Graciela Kaminsky and seminar participants at the International Monetary Fund, Cambridge University and ADEMU "Sovereign Debt in the 21st Century" conference for useful comments. The views expressed herein are those of the authors only and do not represent the views of the IMF, its Executive Board, IMF management, European Central Bank or any institution with which the authors are affilliated.
} 


\section{Contents}

1 Introduction $\quad \underline{4}$

2 A bare-bones model of sovereign debt crises $\quad \underline{7}$

2.1 Optimal default and taxation plans under discretion . . . . . . . . . . $\underline{9}$

2.2 Debt pricing . . . . . . . . . . . . . . . . . . 10

2.3 Rational expectations equilibrium and regularity conditions . . . . . . . 11

2.4 Equilibria ............................... 11

3 The effect of tranching when senior debt is riskless $\underline{14}$

3.1 A Modigliani-Miller irrelevance result . . . . . . . . . . . . . $\underline{16}$

3.2 Non-neutrality . . . . . . . . . . . . . . . . . . . . . . . . . 19

4 Risky senior debt $\quad \underline{22}$

5 A numerical illustration $\quad \underline{24}$

6 Conclusion $\quad \underline{26}$

7 Appendix $\quad \underline{30}$

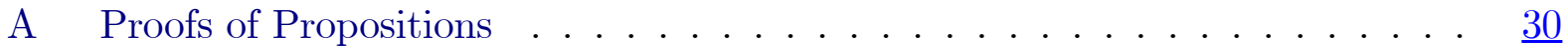

A.1 Proof of Proposition $1 \ldots \ldots \ldots \ldots$

A.2 Proof of Proposition $2 \ldots \ldots \ldots \ldots$

A.3 Proof of Proposition $3 \ldots \ldots \ldots \ldots$

A.4 Proof of Proposition $4 \ldots \ldots \ldots \ldots$

B Equilibria under tranching ................. . 40 


\section{Introduction}

Tranching of public debt features prominently in recent debates on the European sovereign debt crisis, with particular attention devoted to proposals for jointly issued "Eurobonds", that would be senior relative to national sovereign debt (see e.g. Brunnermeier et al., 2016; Delpla and von Weizsäcker, 2010; European Commission, 2011). ${ }^{1}$ More generally, governments in countries with weak economic and fiscal fundamentals often pursue tranching by granting seniority to official creditors or issuing a portion of their bonds under foreign jurisdiction. In such cases, seniority is often associated not only with priority in the repayment order, but with a stronger commitment to repayment. ${ }^{2}$

While tranching and seniority are typically discussed in relation to the need to create a 'safe asset' in economies with risky debt, they also raise a number of important questions concerning fiscal policy and debt sustainability. First and foremost, can issuing senior and junior debt affect prospective (state-contingent) primary deficits, by strengthening the government incentive to raise revenue through distortionary instruments, as opposed to undergoing costly default? The question is whether the revenue that the government generates to service its debt is independent of the seniority structure of public debt, that is, whether this form of 'financial engineering' is neutral with respect to overall debt sustainability.

Second, if the seniority structure of government debt is not neutral for fiscal policy, can a government rely on it to contain vulnerability to self-fulfilling debt crises? In other words, can managing the seniority structure be seen as an instrument to shield sovereign debt from arbitrary, highly destabilizing, market dynamics — without any need for the central bank to provide a monetary backstop to government debt, or for an external lender of last resort?

In this paper, we build a stylized framework to address these questions. In the model, default is costly and a discretionary government trades off distortionary taxation against an optimal haircut to bondholders. Our key result is that the effect of tranching, when associated with plausible, marginally higher default costs on senior bonds, is highly nonlinear in the size of the senior tranche. We show that the seniority structure is irrelevant

\footnotetext{
${ }^{1}$ We use the term Eurobonds to refer to (proposed) government bonds issued jointly by member states of the euro area.

${ }^{2}$ Defaulting on sovereign bonds issued under foreign law may result in more severe penalties compared to defaulting on their counterparts under domestic law. Similarly, defaulting on official creditors could be more costly than defaulting on private creditors.
} 
(but for the relative price of bonds) when the senior tranche is either small or very large. In these cases, a version of the Modigliani and Miller (1958) theorem holds: issuing more or less senior debt at the margin does not affect state-contingent primary surpluses, but only the distribution of cash flows across bond types. However, intermediate levels of tranching may reduce the cost of financing and increase the incentive for the government to service not only senior, but also junior tranches. A key implication is that seniority can prevent sovereign default, addressing the instability created by self-fulfilling debt crises.

We provide analytical and economic insights on this result using a bare-bones model of debt crises. Households are risk neutral and may invest their endowment either in a safe asset or (risky) sovereign bonds. The government is benevolent in that it seeks to maximize household welfare, but discretionary in that it may not pre-commit to repaying its debt. To meet its financing needs, the government sells sovereign bonds at a market price. When debt repayments come due, the government optimally chooses the level of taxation, whether to default on its debt, and if it chooses to default, the extent of the haircut. In the model, household expectations about sovereign default affect the government's borrowing costs and incentives to default, raising the possibility of multiple equilibria. In a 'bad equilibrium', high sovereign yields in anticipation of default risk raise the amount of distortionary taxation required to repay debt, therefore making default preferable. Vulnerability to this bad equilibrium hinges on the initial financing need of the government.

Our main results are as follows. First, we characterize a threshold below which issuing senior bonds simply leads the government to increase the haircut on junior bondholders in order to repay the senior tranche. Tranching is neutral for everything but the relative price of (or interest rates on) senior and junior debt - taxes, default incentives (on the junior tranche) and the overall cost of borrowing for the government remain unchanged. Tranching simply redistributes a given cash flow among holders of different types of debt. Once the senior tranche size exceeds this threshold, however, default on the junior tranche in some state realizations may be complete.

Our second result concerns equilibria conditional on senior debt being large enough that the default on junior bonds is 100 percent - so that there are no residual cash flows to redistribute from junior to senior bondholders: the government may only avoid default on senior bonds by raising tax revenues. We show that if, plausibly, there is a default cost differential, the extra costs associated with reneging on senior liabilities create a discontinuity 
in the government's optimal fiscal policy. Depending on the cost differential, the government may choose to increase revenues, rather than defaulting on senior bonds. ${ }^{3}$

We show that this discontinuity has far reaching consequences on debt pricing and sustainability. Namely, to the extent that higher total payments to bondholders reduce ex-ante borrowing costs, a higher valuation of sovereign bonds at issuance reduces the incentive for the government to default on all, junior and senior, bonds. A key result from our analysis is that, potentially, this effect may eliminate bad equilibria with self-fulfilling default altogether. Depending on the cost of default on senior bonds, however, raising the senior tranche size to very high levels eventually makes default attractive again. Our final result is that there is a upper threshold above which senior debt issuance causes the government to default on both junior and senior debt — reinstating the validity of the Modigliani-Miller ineffectiveness result proven for low levels of tranching.

Our paper relates to a large literature on debt crises which includes Cole and Kehoe (2000), Lorenzoni and Werning (2013), and Nicolini et al. (2015) among many others. We build upon the framework in Calvo (1988). While we introduce fixed costs of default as in Corsetti and Dedola (2016), our focus is on tranching instead of monetary backstops. Similar to Hatchondo et al. (2017), we find that tranching may reduce the government's borrowing costs. However, our framework differs from this literature in two fundamental ways. First, we allow for default on the senior tranche, which effectively places an upper bound on the senior tranche size. Second, since the government optimally determines the haircut, we account for the possibility that tranching may reduce payments to junior bondholders.

Our paper is also closely related to the recent literature on Eurobonds. ${ }^{4}$ Delpla and von Weizsäcker (2010) propose the creation of a senior tranche of jointly issued sovereign debt guaranteed by all euro area member states, while nationally issued debt becomes a junior tranche. To preserve market discipline, their proposal restricts the amount of senior bonds each country may issue. Muellbauer (2011) and German Council of Economic Experts (2012) argue that joint liability should be combined with conditionalities to prevent moral hazard while Philippon and Hellwig (2011) suggest restricting Eurobonds to only short term maturities.

\footnotetext{
${ }^{3}$ It is worth re-iterating that if the costs of default are the same for junior and senior debt, the seniority structure would still be irrelevant: the government would start imposing a haircut on the holders of senior bonds.

${ }^{4}$ See Eijffinger (2011) for a summary of the earlier proposals.
} 
In these studies, the main benefit of Eurobonds is to pool risk and prevent liquidity runs on individual countries through mutualization, while tranching serves to alleviate moral hazard. In a different vein, Beck et al. (2011) and Brunnermeier et al. (2016, 2017) analyze Eurobonds without joint guarantees. Rather than risk sharing, these studies focus on the benefits of providing a safe asset for banks in default-risky countries through a combination of diversification and tranching.

We contribute to this literature by bringing to attention an additional reason for tranching: costly default. In our framework, there is neither scope for risk pooling, nor any demand for safe assets, that is, the irrelevance results from Modigliani and Miller (1958) hold in the absence of costly default. We show that introducing differential default costs into this framework creates a non-linear relationship between tranching and government incentives to tax and default, potentially eliminating default risk from not only the senior tranches but also the junior.

We proceed as follows: Section 2 describes a bare-bones model of self-fulfilling debt crises. Section 3 introduces tranching. Section 4 considers default on senior debt. Section 5 provides a numerical illustration. Section 6 concludes.

\section{A bare-bones model of sovereign debt crises}

Consider a two-period endowment economy populated by a unit continuum of identical riskneutral households which derive utility from consuming in period 2 only. In the first period, households are endowed with a stock of financial wealth $W_{0}$ which they can invest in two assets: public debt $B$ issued at an endogenous market price $q_{b}$ and a safe asset $K$ sold at exogenously given price $q$ with an infinitely elastic supply. ${ }^{5}$ Households' period 1 budget constraint can then be written as

$$
W_{0}=q_{b} B+q K
$$

In period 2, households receive a random output realization: it may be "high" $Y_{H}$ and "low" $Y_{L}$ with probabilities $(1-\gamma)$ and $\gamma$ respectively. Households also receive payoffs from their assets, pay taxes, and consume, leading to the set of budget constraints

\footnotetext{
${ }^{5}$ In the interest of tractability, we model $B, K$ as discount bonds
} 


$$
C_{i}=Y_{i}-z_{i}\left(T_{i}\right)-T_{i}+K+\left(1-\theta_{i}\right) B-\Phi_{i} \forall i \in\{L, H\}
$$

where $i \in\{L, H\}$ indexes the state of nature, $C_{i}$ is consumption, $T_{i}$ is the tax bill and $z_{i}\left(T_{i}\right)$ captures dead-weight losses associated with tax distortions. $\theta_{i} \in[0,1]$ represents a potential haircut on public debt which leads to a fixed default cost on the economy

$$
\Phi_{i}=\left\{\begin{array}{c}
\Phi \text { if } \theta_{i}>0 \\
0 \text { otherwise }
\end{array}\right.
$$

In line with the literature on tax smoothing, we posit that $z_{i}($.$) is strictly convex and$ that at a given level of tax revenues, dead-weight losses are larger and grow faster in taxation in the state with lower output, that is

$$
\begin{aligned}
& z_{L}(.)>z_{H}(.) \\
& z_{L}^{\prime}(.)>z_{H}^{\prime}(.)
\end{aligned}
$$

The government is benevolent - it seeks to maximize the utility of the representative household - but lacks the ability to commit ex-ante to a tax schedule. In period 1 , the government rolls over its (exogenous) financing need $B_{0}$ by issuing discount bonds $B=B_{0} / q_{b}$. In period 2, the government observes the output realization and set tax and haircut rates under discretion, consistent with its budget constraint

$$
T_{i}-G=\left(1-\theta_{i}\right) B+\alpha \theta_{i} B
$$

where $\alpha \in(0,1)$ represents a budgetary cost of default proportional to defaulted payments and $G$ is public spending. Since what matters in our analysis is the size of the primary surplus rather than individual budget components, we posit without loss of generality that $G$ is a parameter invariant across states of nature. 


\subsection{Optimal default and taxation plans under discretion}

The government's optimization problem can be written as

$$
\max _{T_{i}>0, \theta_{i} \in[0,1]} Y_{i}-z_{i}\left(T_{i}\right)-\Phi_{i}-T_{i}+K+\left(1-\theta_{i}\right) B
$$

subject to (4). Due to the boundary constraints on the haircut, there are two corner solutions, respectively with no default $\left(\theta_{i}=0\right)$ and complete default $\left(\theta_{i}=1\right)$, as well as an interior

solution $\theta_{i}=\hat{\theta}_{i} \in(0,1)$. We find it convenient to begin with a description of the interior solution, where tax revenues are pinned down by a first order condition

$$
z_{i}^{\prime}\left(\hat{T}_{i}\right)=\frac{\alpha}{1-\alpha}
$$

that trades-off marginal tax distortions against (fractional) budgetary default costs. Combining (4) and (5) yields an expression for the (interior) haircut

$$
\hat{\theta}_{i}=\frac{1}{1-\alpha}\left(1-\frac{\hat{T}_{i}-G}{B}\right)
$$

These expressions indicate that, in an interior solution, tax revenues are not affected by a rise in the public debt bill $B$. Rather, additional debt simply increases the size of the haircut. In contrast, in states with lower (marginal) tax distortions as per (3), the government optimally collects more tax revenues and reduces the haircut. In other words, the government uses the haircut to smooth tax distortions across states of nature.

The fixed costs $\Phi$ associated with default create a discontinuity in the government's problem such that default is optimal only when it increases household welfare (i.e. consumption). This leads to the default condition

$$
z_{i}(G+B)>z_{i}\left(T_{i}\right)+\Phi+\alpha \theta_{i} B
$$

When considering an interior solution, the default condition can be written in terms of a "minimum haircut" $\underline{\theta}_{i}$, defined implicitly by the expression

$$
z_{i}\left(\hat{T}_{i}\right)+\Phi=z_{i}\left(\hat{T}_{i}+\frac{\underline{\theta}_{i}(1-a)}{1-\underline{\theta}_{i}(1-a)}\left(\hat{T}_{i}-G\right)\right)-\frac{a \underline{\theta}_{i}}{1-\underline{\theta}_{i}(1-a)}\left(\hat{T}_{i}-G\right)
$$


such that the interior solution is optimal for $\hat{\theta}_{i} \geq \underline{\theta}_{i}$. Observe that $\underline{\theta}_{i}$ is increasing in the fixed default cost $\Phi$ but independent of $B$. Moreover, the minimum haircut is higher in states with less tax distortions, that is $\underline{\theta}_{L}<\underline{\theta}_{H}$.

For $\hat{\theta}_{i}<\underline{\theta}_{i}$, optimal policy is characterized by a no-default corner outcome $\theta_{i}=0$ with a tax bill

$$
T_{i}=G+B
$$

that is consistent with complete repayment of debt.

Finally, the corner solution with complete default may be optimal when $\hat{\theta}_{i}>1$. In this case, the relevant default condition is given by combining (7) with $\theta_{i}=1$ such that

$$
z_{i}(G+B)>z_{i}(G+\alpha B)+\Phi+\alpha B
$$

and taxes are set at

$$
T_{i}=G+\alpha B
$$

Observe that in the corner solutions tax revenues become contingent on the debt bill $B$ instead of tax distortions: facing constraints on its ability to adjust the haircut, the government sets taxes according to its debt repayment plans rather than marginal distortions. This also implies that tax revenues cease to be state-contingent.

To summarize, the government's optimal policy plan is written compactly in Table 1.

Table 1: Government's optimal discretionary plan

$$
\begin{array}{lll}
\text { If } \hat{\theta}_{i}>1, z_{i}(G+B)>z_{i}(G+\alpha B)+\Phi+\alpha B: & \theta_{i}=1 & T_{i}=G+\alpha B \\
\text { If } \hat{\theta}_{i} \in\left[\underline{\theta}_{i}, 1\right]: & \theta_{i}=\hat{\theta}_{i} & T_{i}=\hat{T}_{i}=z_{i}^{\prime-1}\left(\frac{\alpha}{1-\alpha}\right) \\
\text { Otherwise : } & \theta_{i}=0 & T_{i}=G+B
\end{array}
$$

\subsection{Debt pricing}

The price of public debt is pinned down by an interest parity condition, which equates (under risk neutrality) the expected returns on government bonds with those of safe assets

$$
q_{b}=q\left[(1-\gamma)\left(1-\theta_{H}\right)+\gamma\left(1-\theta_{L}\right)\right]
$$


Given the government's need to roll over its initial financing need $B_{0}$, any decline in the price of its bonds $q_{b}$ due to expectations of default leads to a rise in market financing $B=D / q^{b}$, raising the government's debt burden in period 2. We capture this in a market financing schedule

$$
B=\frac{B_{0}}{q\left[(1-\gamma)\left(1-\theta_{H}\right)+\gamma\left(1-\theta_{L}\right)\right]}
$$

\subsection{Rational expectations equilibrium and regularity conditions}

Under rational expectations, households anticipate the optimal discretionary plan of the government conditional on its debt $B$. The market financing schedule (11), together with the government budget constraint (4), the expressions for interior and minimum haircuts respectively given by (6) and (8), and the government's optimal discretionary plan as described in Table 1 define a rational expectations equilibrium.

To rule out equilibria on the right side of the debt-Laffer curve's peak (i.e. where the price of public debt $q_{b}$ is increasing in the government's financing need $B_{0}$ ), we impose the following regularity restrictions

$$
\begin{aligned}
z_{H}^{\prime}\left(\hat{T}_{H}\right) & \rightarrow 0 \\
1-\gamma & >\alpha
\end{aligned}
$$

which rule out default in the high output state $\left(\theta_{H}=0\right)$ in order to place a lower bound on $q_{b}$.

To keen our exposition as compact as possible, in the remainder of the paper we drop the subscript $L$. Therefore, the market financing schedule (11) becomes

$$
B=\frac{B_{0}}{q(1-\gamma \theta)}
$$

where $\theta$ refers to the haircut in state $L$.

\subsection{Equilibria}

As in our economy there may be two possible equilibrium types, one with and one without default, we adopt the following notation. Variables in a no-default equilibrium will be written 
with a superscript " $N D E$ ", whereas $\theta^{N D E}=0$; the superscript " $D E$ " will be use for the equilibrium with default, whereas the haircut $\theta^{D E}>0$ will be strictly positive in state $L$. Proposition 1 characterizes these equilibria and shows that they exist in regions of financing need $B_{0}$ that line up monotonically, that is, as $B_{0}$ rises, we move from a region of $N D E$ to $D E$. Most importantly, the proposition shows that, when there is a fixed default cost $\Phi>0$, these two regions overlap leading to multiple equilibria.

Proposition 1 Let

$$
\begin{aligned}
\bar{B}_{0} & \equiv \frac{q(\hat{T}-G)}{1-(1-\alpha) \underline{\theta}} \\
\underline{B}_{0} & \equiv(1-\gamma \underline{\theta}) \frac{q(\hat{T}-G)}{1-(1-\alpha) \underline{\theta}}
\end{aligned}
$$

For $B_{0}<\bar{B}_{0}, N D E$ is self-confirming such that

$$
\begin{aligned}
q_{b}^{N D E} & =q \\
B^{N D E} & =B_{0} / q \\
\theta^{N D E} & =0 \\
T^{N D E} & =G+B^{N D E}
\end{aligned}
$$

and for $B_{0} \geq \underline{B}_{0}, D E$ is self-confirming and characterized by

$$
\begin{aligned}
\theta^{D E} & =\min \left[\frac{B_{0}-(\hat{T}-G) q}{(1-\alpha) B_{0}-\gamma(\hat{T}-G) q}, 1\right] \\
q_{b}^{D E} & =\left\{\begin{array}{cc}
q(1-\gamma) & \text { if } \theta^{D E}=1 \\
\frac{(1-\alpha-\gamma) q B_{0}}{(1-\alpha) B_{0}-\gamma q(\hat{T}-G)} & \text { otherwise }
\end{array}\right. \\
B^{D E} & =B_{0} / q_{b}^{D E} \quad \begin{array}{l}
G+\alpha B^{D E} \text { if } \theta=1 \\
\hat{T} \quad \text { otherwise }
\end{array} \\
T^{D E} & =\left\{\begin{array}{l}
\hat{T}^{D E}
\end{array}\right.
\end{aligned}
$$


Finally, there are multiple equilibria when financing needs are within the region

$$
\underline{B}_{0} \leq B_{0}<\bar{B}_{0}
$$

which is non-empty for $\Phi>0$.

Proof. See Appendix A.1.

We provide intuition about the mechanism generating multiplicity with the use of a graphical example in Figure 1. In doing so, we represent the model as a system of three equations: (a) A minimum haircut $\underline{\theta}$ given by (8) which is increasing in the fixed cost of default $\Phi$ and independent of the government's period 2 debt burden $B$, (b) a non-linear optimal haircut schedule $\theta(B)$ described by (6) and Table 1, and (c) a market financing schedule $B\left(\theta, B_{0}\right)$ given by $(12)$.

The market financing schedule is upward sloping as an increase in the anticipated haircut on sovereign bonds reduces their market price $q_{b}$, driving the government to issue more bonds to meet its initial financing need $B_{0}$. The optimal haircut schedule is also upward sloping in the interior region $\theta \in(\underline{\theta}, 1)$ because the government's optimal policy plan prescribes a constant primary surplus $(\hat{T}-G)$ at a level pinned down by marginal distortions as explained in Section 2.1.

Figure 1 illustrates the equilibrium solutions at levels of financing need $B_{0}<B_{0}^{\prime}<B_{0}^{\prime \prime}-$ whereby a higher financing need causes a shift to the right in the market financing schedule. Equilibrium occurs at the combinations of $(B, \theta)$ where the market financing and optimal haircut schedules intersect. At $B_{0}$, these schedules only intersect at $(B, \theta)=\left(\frac{B_{0}}{q}, 0\right)$ such that there is a unique no default equilibrium denoted as $N D E$. In this equilibrium, the government has access to funds at the risk-free rate $q^{-1}$. In contrast, there are multiple equilibria at $B_{0}^{\prime}$ with $N D E^{\prime}$ pointing at an equilibrium with no default and $D E^{\prime}$ at an equilibrium with default in state $L$. The source of multiplicity here is the discontinuity of the optimal haircut in the region $\left[0, \underline{\theta}_{L}\right]$, which stems from the fixed default cost $\Phi>0$. Finally, at $B_{0}^{\prime \prime}$, there is a unique equilibrium $D E^{\prime \prime}$ at the upper corner for haircuts $\theta=1$ such that $B^{D E^{\prime \prime}}=[q(1-\gamma)]^{-1} B_{0}^{\prime \prime}{ }^{6}$

\footnotetext{
${ }^{6}$ This equilibrium is at the upper corner just for purposes of demonstration. There may also be unique default equilibria at an interior solution.
} 
Figure 1: Equilibria across initial debt

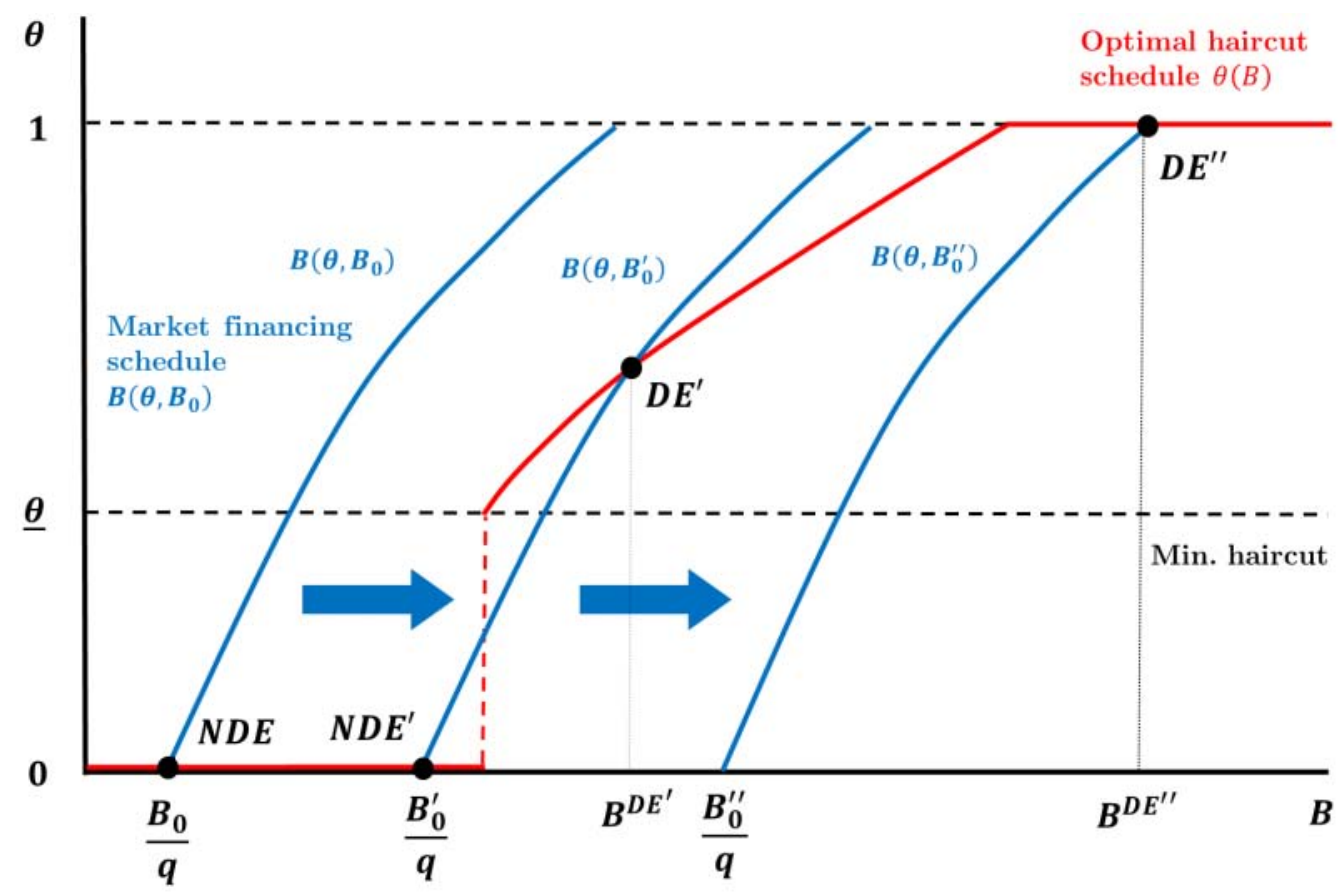

Note: The market financing, minimum haircut and optimal haircut schedules are respectively given by (11), (8) and Table 1.

In the next section, we describe the changes in these equilibrium allocations as a result of interventions that alter the seniority structure of sovereign debt.

\section{The effect of tranching when senior debt is riskless}

In this section, we reconsider the model equilibrium by allowing for a share $0 \leq \omega \leq 1$ of government bonds to have senior status. To begin with, we find it convenient to assume that the senior tranche is free of default risk and priced on par with risk-free assets at $q_{s}=q$. This is equivalent to positing prohibitively high costs of defaulting on senior bonds. We will drop the assumption of non-defaultability in Section 4.

For a given share of senior debt, junior bonds are traded at the price $q_{b}$ reflecting expected returns as per the debt pricing condition (10). The market financing schedule can then be 
written as

$$
\begin{aligned}
B & =B_{0}\left[\omega q+(1-\omega) q_{b}\right]^{-1} \\
& =\frac{B_{0}}{q(1-\gamma(1-\omega) \theta)}
\end{aligned}
$$

where $\theta$ is the haircut on junior bonds. The government's period 2 budget constraint and default condition (for junior bonds) become, respectively

$$
\begin{gathered}
T-G=[\omega+(1-\omega)(1-(1-\alpha) \theta)] B \\
z(G+B)>z(T)+\Phi+\alpha(1-\omega) \theta B
\end{gathered}
$$

in reflection of full repayment of senior bonds.

In an interior solution, the discretionary government internalizes only the budgetary cost $\alpha$ of a marginal increase in the haircut on junior bonds. This leaves the trade-off between tax distortions and default costs same as in Section 2.1 with (5) determining the primary surplus $(\hat{T}-G)$ independently of the senior tranche size $\omega$. A key implication is that, in the absence of a rise in the primary surplus, tranching leads to the re-allocation of repayments from junior to senior bondholders. To avoid default on the senior tranche, the government haircuts bonds in the junior tranche by

$$
\hat{\theta}=\frac{1}{(1-\omega)(1-\alpha)}\left(1-\frac{\hat{T}-G}{B}\right)
$$

which is increasing in $\omega$.

Note also that tranching reduces the revenues gained from default at a given haircut. With a fixed default cost $\Phi>0$, this increases the minimum haircut $\underline{\theta}$ required to make (interior) default optimal. $\underline{\theta}$ is implicitly defined by the expression

$$
\begin{aligned}
z(\hat{T})+\Phi= & z\left(\hat{T}+\frac{(1-\omega)(1-\alpha) \underline{\theta}}{\omega+(1-\omega)(1-(1-\alpha) \underline{\theta})}(\hat{T}-G)\right) \\
& -\frac{\alpha(1-\omega) \underline{\theta}}{\omega+(1-\omega)(1-(1-\alpha) \underline{\theta})}(\hat{T}-G)
\end{aligned}
$$

and positively related to $\omega$ while remaining independent of $B$. 
For $\hat{\theta}<\underline{\theta}$, the optimal policy plan is free of default and remains identical to the case without tranching. For $\hat{\theta}>1$ and

$$
z(G+B)>z(G+(\omega+(1-\omega) \alpha) B)+\Phi+\alpha(1-\omega) B
$$

the optimal policy plan involves complete default $\theta=1$ on junior bonds. In this case, tax revenues are given by the expression

$$
T=G+[\omega+(1-\omega) \alpha] B
$$

and naturally increasing in the share of senior bonds $\omega$, which must still be repaid in full. Finally, Table 2 summarizes the revised optimal policy plan under tranching, where the first two columns describe the government's optimal haircut schedule for junior bonds

Table 2: Government's optimal plan under tranching

$$
\begin{array}{llrl}
\text { If } \hat{\theta}>1, z(G+B)>z(G+(\omega+(1-\omega) \alpha) B): & \theta=1 & T=G+[\omega+(1-\omega) \alpha] B \\
+\Phi+\alpha(1-\omega) B & & & \\
\text { If } \hat{\theta} \in[\underline{\theta}, 1]: & \theta=\hat{\theta} & T=\hat{T}=z^{\prime-1}\left(\frac{\alpha}{1-\alpha}\right) \\
\text { Otherwise : } & \theta=0 & T=G+B
\end{array}
$$

Observe that, on the one hand, tranching moves the optimal haircut towards complete default on junior bonds (i.e. the upper corner solution with $\theta=1$ ) since both the interior and minimum haircut expressions $(\hat{\theta}, \underline{\theta})$ increase in $\omega$. On the other hand, with sufficiently high $\omega$, the default condition in the upper corner given by (21) is not satisfied such that tranching may eliminate default. ${ }^{7}$ Elaborating on these two effects, in the rest of the section we will analyze whether and under what conditions tranching sovereign debt may prevent debt crises. A full description of equilibria under tranching is provided in the Appendix B.

\subsection{A Modigliani-Miller irrelevance result}

We start by establishing that, as long as the optimal haircut lies in the interior region, tranching changes neither the equilibrium boundaries (in terms of government financing

\footnotetext{
${ }^{7}$ See Appendix A.2 for a formal proof that $\underline{\theta}$ is positively related to $\omega$ and Appendix A.3 for a proof that sufficiently high $\omega$ eliminates default.
} 
needs $B_{0}$ ) nor the government's debt bill $B$. This stems from our earlier finding that the government optimally increases the haircut on junior bonds to fully repay the senior tranche. In anticipation of a lower expected return, investors discount junior bond prices $q_{b}$ which, under risk neutrality, exactly offsets the move to a risk-free price $q$ in the senior tranche.

Proposition 2 Let $\underline{\omega}$ denote the minimum senior tranche size that leads to a corner solution in the default equilibrium $(D E)$ such that

$$
\begin{gathered}
\underline{\omega} \equiv \frac{(1-\gamma)(\hat{T}-G)-\alpha \frac{B_{0}}{q}}{(1-\alpha) \frac{B_{0}}{q}-\gamma(\hat{T}-G)} \in[0,1) \\
\frac{\partial \underline{\omega}}{\partial B_{0}}<0
\end{gathered}
$$

For all $\omega<\underline{\omega}$, we can write

$$
\begin{gathered}
T^{D E}=\hat{T} \\
\theta^{D E}=\frac{1}{1-\omega} \frac{\frac{B_{0}}{q}-(\hat{T}-G)}{(1-\alpha) \frac{B_{0}}{q}-\gamma(\hat{T}-G)}<1 \\
\frac{\partial \theta^{D E}}{\partial \omega}>\frac{\partial \underline{\theta}}{\partial \omega}>0 \forall B_{0}>\underline{B}_{0} \\
\frac{\partial B^{D E}}{\partial \omega}=\frac{\partial \bar{B}_{0}}{\partial \omega}=\frac{\partial \underline{B}_{0}}{\partial \omega}=0
\end{gathered}
$$

where $\left(B^{D E}, \underline{\theta}, \bar{B}_{0}, \underline{B}_{0}\right)$ are respectively given by (15), (20), (13) and (14).

Proof. See Appendix A.2.

This finding is naturally interpreted in light of Modigliani and Miller (1958)'s irrelevance result. Without a change in total payments to bondholders, tranching is irrelevant under risk neutrality. In other words, the price of bond, $\omega q+(1-\omega) q_{b}$, and the debt bill $B$ are independent of $\omega$ such that tranching has no impact on government incentives to default. Constancy of the marginal (budgetary) default cost $\alpha$ and hence the (interior) primary surplus $(\hat{T}-G)$ are crucial for this result; were $\alpha$ to increase (decrease) in $\theta$, tranching would lead to a rise (fall) in the primary surplus and lower (higher) government borrowing costs and incentives to default. 
Figure 2: Tranching at an interior equilibrium

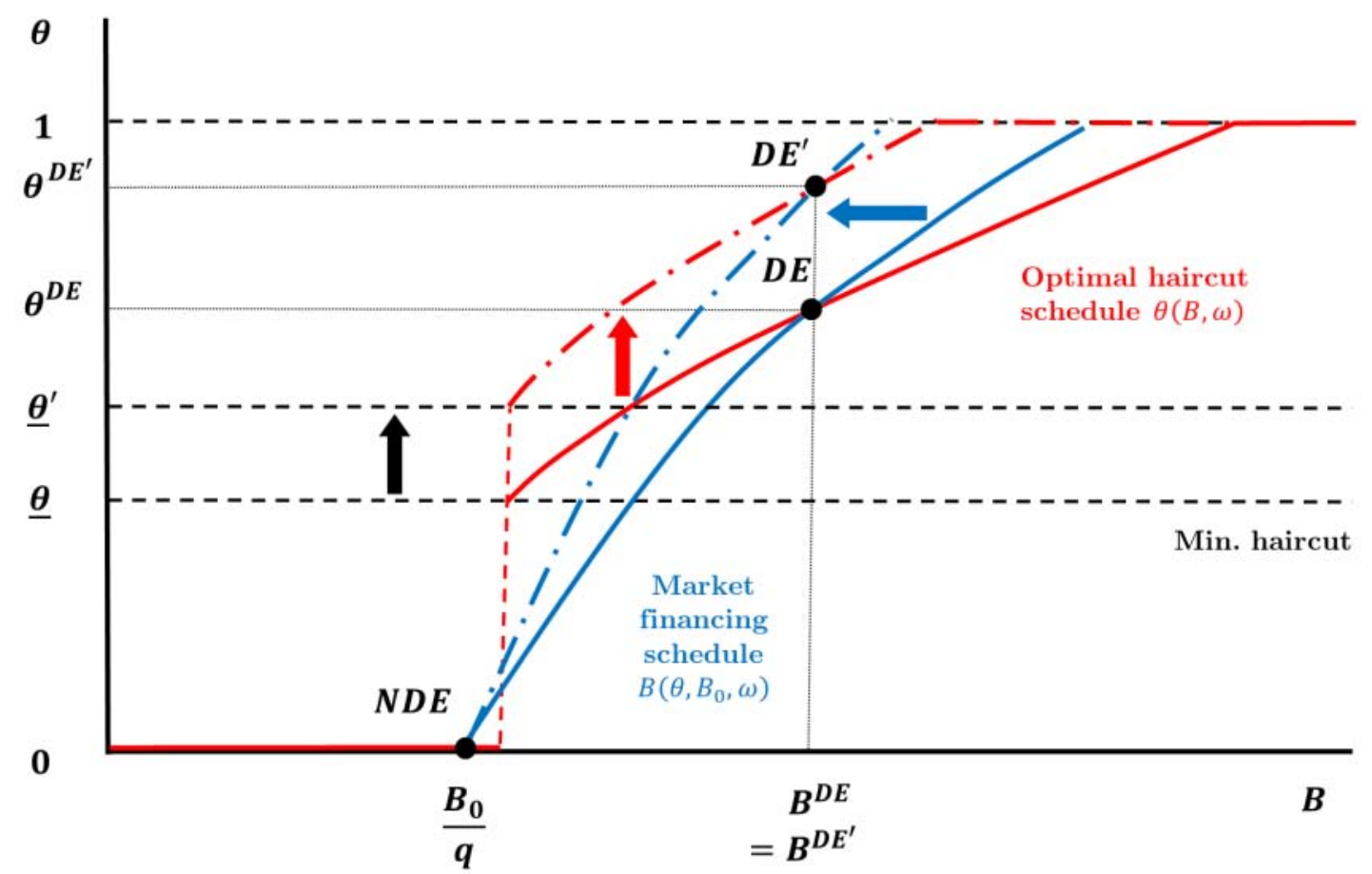

Note: The market financing, minimum haircut and optimal haircut schedules are respectively given by (16), (20) and Table 2. The market financing schedule reflects the total debt bill while the minimum haircut and the optimal haircut schedule pertain to junior bonds.

We use Figure 2 to provide further intuition. At senior tranche size $\omega$, the market financing and optimal haircut schedules intersect twice, leading to multiple equilibria. First, there is a no default equilibrium $(N D E)$ with no haircut on public debt and bonds issued at the risk-free price $B^{N D E}=B_{0} / q$. Second, there is a default equilibrium $(D E)$ with a haircut $\theta^{D E}$ on junior bonds. In this equilibrium, the anticipation of default leads to a reduction in junior bond prices and a higher debt bill $B^{D E}$.

Increasing the size of the senior tranche to $\omega^{\prime}>\omega$ has three distinct effects. First, it pivots the market financing schedule $B\left(\theta, B_{0}, \omega\right)$ leftward. Provided that investors anticipate a default, senior bonds are sold at a higher price $q>q_{b}$ than junior bonds. Therefore, issuing a greater share of its debt in a senior tranche reduces the government's total debt bill $B$ at a given haircut for junior bonds. Second, it increases the minimum haircut from $\underline{\theta}$ to $\underline{\theta}^{\prime}$. A rise in the share of senior bonds reduces the "default base" from which the government may extract resources through default. This necessitates a larger haircut to make default 
optimal given a fixed default cost $\Phi$. Third, it causes an upward shift in the optimal haircut schedule $\theta(B, \omega)$ within the interior region. Since the primary surplus remains constant in an interior solution, the government increases the haircut on junior bonds in order to fully repay a larger share of senior bonds.

$N D E$ naturally remains unchanged in response to the rise in $\omega$ as there is no distinction between senior and junior tranches without default risk. In contrast, the default equilibrium moves from $D E$ to $D E^{\prime}$ due to the first and third effects. As explained above, the haircut on junior bonds rises from $\theta^{D E}$ to a level $\theta^{D E \prime}$ that exactly offsets any movements in the government's debt bill $B^{D E}$. Moreover, Proposition 2 indicates that $\theta^{D E}$ rises by a greater amount than the minimum haircut $\underline{\theta}$. Therefore, equilibrium boundaries are not affected and tranching is ineffective at eliminating debt crises.

\subsection{Non-neutrality}

The irrelevance result above is conditional on an interior solution $\theta^{D E}<1$. We now show that our version of the Modigliani-Miller theorem fails when default rates on junior bonds are at the corner, that is, default is complete.

In Figure 2, an increase in the share of senior debt $\omega$ drives the optimal haircut towards the upper corner. Proposition 2 establishes that there is a threshold $\underline{\omega}$ such that, for any share of the senior debt in excess of it, $D E$ has a corner solution with $\theta^{D E}=1$. We now show that, at the corner solution, the findings for the interior case are reversed: increasing $\omega$ reduces the government's borrowing costs and the total debt bill $B$, and eventually eliminates default. These findings are formally stated by Proposition 3 below. This proposition also shows that the minimum senior tranche share $\omega^{*} \in(\underline{\omega}, 1)$ required to eliminate default increases in the government's financing need $B_{0}$.

Proposition 3 For $\omega>\underline{\omega}$, the default equilibrium has a corner solution characterized by

$$
\begin{gathered}
\theta^{D E}=1 \\
T^{D E}=G+(\omega+(1-\omega) \alpha) B^{D E} \\
B^{D E}=\frac{B_{0}}{q(1-\gamma(1-\omega))}
\end{gathered}
$$


such that

$$
\begin{aligned}
& \frac{\partial T^{D E}}{\partial \omega}>0 \\
& \frac{\partial B^{D E}}{\partial \omega}<0
\end{aligned}
$$

There exists a minimum senior tranche $\omega^{*}$ above which there is no default, implicitly defined by the expression

$$
\begin{aligned}
z\left(G+\frac{1}{1-\gamma\left(1-\omega^{*}\right)} \frac{B_{0}}{q}\right)= & z\left(G+\frac{\omega^{*}+\left(1-\omega^{*}\right) \alpha}{1-\gamma\left(1-\omega^{*}\right)} \frac{B_{0}}{q}\right) \\
& +\Phi+\frac{\left(1-\omega^{*}\right) \alpha}{1-\gamma\left(1-\omega^{*}\right)} \frac{B_{0}}{q}
\end{aligned}
$$

such that

$$
\begin{gathered}
\underline{\omega}<\omega^{*}<1 \\
\frac{\partial \omega^{*}}{\partial B_{0}}>0
\end{gathered}
$$

Proof. See Appendix A.3.

The key insight here is that the government may not respond to tranching by increasing the haircut on junior bonds when it is already at the upper corner. Instead, it is driven to increase tax revenues in order to fully repay the senior tranche. Since tranching leads to a rise in total payments to bondholders, the ineffectiveness result from Modigliani and Miller (1958) no longer holds.

There are two distinct channels through which tranching affects the government's default decision. First, without a rise in the haircut, junior bond prices $q^{b}$ remain constant in response to an increase in $\omega$. As bonds in the senior tranche trade at a higher price $q>q^{b}$, tranching reduces the government's average borrowing costs $\left(\omega q+(1-\omega) q^{b}\right)^{-1}$ and total debt bill $B$. Consequently, tax revenues $T=G+B$ required to avoid default and the associated tax distortions decrease.

Second, with higher tax revenues needed to repay senior bonds during default, tax distortions $z(G+(\omega+(1-\omega) \alpha) B)$ under default increase with a rise in $\omega$. Together, these two channel decrease the potential reduction in tax distortions by defaulting on public debt and 
Figure 3: Tranching to eliminate default

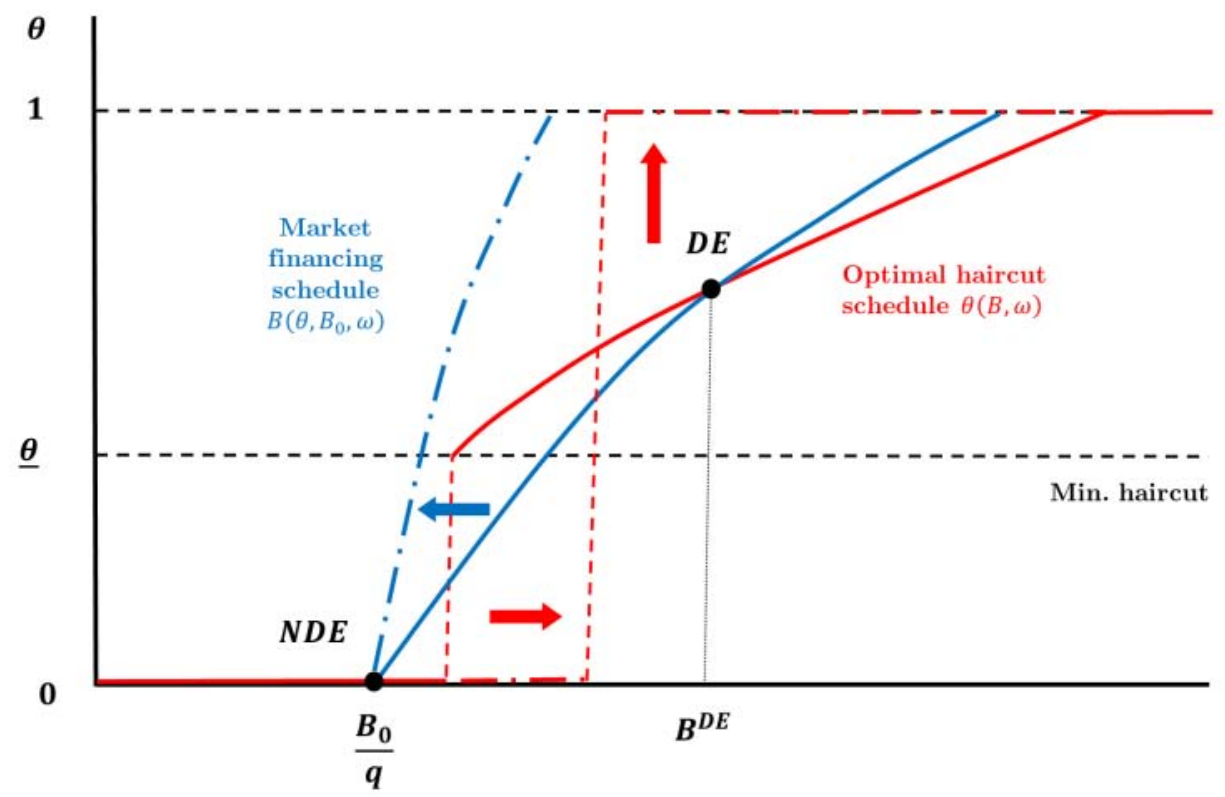

Note: The market financing, minimum haircut and optimal haircut schedules are respectively given by (16), (20) and Table 2. The market financing schedule reflects the total debt bill while the minimum haircut and the optimal haircut schedule pertain to junior bonds.

therefore the government's temptation to do so. Given the fixed cost of default, a sufficiently large senior tranche then prevents default.

Finally, we use Figure 3 to contrast the effects of tranching in a corner solution with the interior case shown in Figure 2. The baseline scenario with multiple equilibria ( $N D E, D E)$ is identical in the two figures but $\omega^{\prime \prime}$ in Figure 3 is sufficiently large to move the minimum haircut $\underline{\theta}$ to the upper corner. Consequently, the optimal haircut schedule $\theta\left(B_{0}, \omega\right)$ loses its interior region and jumps directly from no default to a complete haircut at a boundary determined by (21). An increase in $\omega$ moves the default boundary to the right while the market financing schedule $B\left(\theta, B_{0}, \omega\right)$ pivots leftward as in Figure 2 . When the senior tranche is large enough, the market financing and optimal haircut schedules no longer intersect above $\theta=0$, and the default equilibrium $D E$ is eliminated.

Note that, as before, $N D E$ is not affected by tranching since seniority is irrelevant in the absence of default risk. Indeed, when tranching is successful in ruling out debt crises, the prospect of a complete haircut on junior bonds remains completely off-equilibrium and both junior and senior bonds are priced at risk free level $q_{b}=q$. 


\section{Risky senior debt}

In this section, we move away from the extreme assumption that the senior tranche is nondefaultable. We show that our main results generalize to the plausible case in which, even if the costs of defaulting on senior bonds are larger than for junior bonds, the government may (choose to) default also on senior bonds The government's budget constraint and market financing schedule now are:

$$
\begin{aligned}
T-G & =\left[\omega\left(1-(1-\alpha) \theta_{s}\right)+(1-\omega) \alpha\right] B \\
B & =\frac{B_{0}}{q\left[1-\gamma+\gamma \omega\left(1-\theta_{s}\right)\right]}
\end{aligned}
$$

where $\theta_{s}$ denotes the haircut on the senior tranche, and the prices of senior and junior bonds are respectively given by

$$
\begin{aligned}
& q_{s}=q\left(1-\gamma \theta_{s}\right) \\
& q_{b}=q(1-\gamma)
\end{aligned}
$$

In an interior solution, the haircut on the senior tranche is determined by the expression

$$
\hat{\theta}_{s}=\frac{1}{\omega(1-\alpha)}\left(\omega+\alpha(1-\omega)-\frac{\hat{T}-G}{B}\right)
$$

with taxes $\hat{T}$ pinned down by the same first order condition (5) as before. Similarly, in a corner solution with complete default on both tranches $\left(\theta_{s}=\theta=1\right)$, taxes are given by

$$
T=G+\alpha B
$$

Proposition 4 describes a "senior default equilibrium" ( $S D E)$ where the government optimally defaults on both tranches.

Proposition 4 Let SDE denote an equilibrium where the government defaults on the senior 
tranche. SDE is characterized by

$$
\begin{aligned}
\theta_{s}^{S D E} & =\min \left[\frac{1}{\omega} \frac{(\omega+\alpha(1-\omega)) \frac{B_{0}}{q}-(1-\gamma(1-\omega))(\hat{T}-G)}{(1-\alpha) \frac{B_{0}}{q}-\gamma(\hat{T}-G)}, 1\right] \\
\theta^{S D E} & =1 \\
B^{S D E} & = \begin{cases}\frac{B_{0}}{q(1-\gamma)} & \text { if } \theta_{s}^{S D E}=1 \\
\frac{(1-\alpha) \frac{B_{0}}{q}-\gamma(\hat{T}-G)}{1-\alpha-\gamma} & \text { otherwise }\end{cases} \\
T^{S D E} & = \begin{cases}G+\alpha B^{S D E} & \text { if } \theta_{s}^{S D E}=1 \\
\hat{T} & \text { otherwise }\end{cases}
\end{aligned}
$$

and self-confirming for all $\omega>\bar{\omega}$ where $\bar{\omega}$ is implicitly defined by the expression

$$
z\left(G+(\bar{\omega}+(1-\bar{\omega}) \alpha) B^{S D E}\right)=z\left(T^{S D E}\right)+\Phi_{s}+\bar{\omega} \alpha \theta_{s}^{S D E} B^{S D E}
$$

such that

$$
\begin{aligned}
\frac{\partial \bar{\omega}}{\partial \Phi_{s}}>0 \\
\frac{\partial \bar{\omega}}{\partial B_{0}}<0
\end{aligned}
$$

For sufficiently high $\Phi_{s}$, the set $\omega \in\left(\omega^{*}, \bar{\omega}\right)$ is non-empty.

Proof. See Appendix A.4

According to Proposition 4, government's funding costs and taxes are equivalent between $S D E$ and the default equilibrium $D E$

$$
\begin{aligned}
& B^{S D E}=B^{D E} \\
& T^{S D E}=T^{D E}
\end{aligned}
$$

Once the government defaults on the senior tranche, the Modigliani-Miller irrelevance result described in Section 3.1 holds. The government has no incentive to raise tax revenues and average funding costs remain constant regardless of how revenues are allocated between the 
two tranches. Therefore, tranching is ineffective not only when the senior tranche size falls short of $\underline{\omega}$ (and there is an interior haircut on the junior tranche) but also when it exceeds $\bar{\omega}$ leading to default on the senior tranche.

The key implication is that tranching requires higher fixed default costs on the senior tranche to generate commitment to repay. The last part of Proposition 4 indicates that, for sufficiently high $\Phi_{s}$, there exists an intermediate region of senior tranche size $\omega \in\left(\omega^{*}, \bar{\omega}\right)$ where tranching eliminates default. Since $\omega^{*}>\underline{\omega}$, the junior tranche is haircut fully in this region. Provided $\Phi_{s}$ is high enough, however, the government chooses to increase tax revenues rather than defaulting on the senior tranche. The resulting decrease in the government's exante funding costs then eliminate default. Since $\omega^{*}$ is increasing in $B_{0}$ while $\bar{\omega}$ decreases in it, greater government financing needs require higher levels of $\Phi_{s}$ for tranching to be effective.

\section{A numerical illustration}

In this section, we provide a numerical example to demonstrate debt crises in the model economy and the circumstances under which tranching may eliminate these crises.

We adopt the following calibration for the numerical example. For tax distortions, we use the functional form $z_{i}\left(T_{i}\right)=\psi_{i} T_{i}^{2}$ such that tax revenues in the interior solutions are given by $\hat{T}_{i}=\alpha\left[2 \psi_{i}(1-\alpha)\right]^{-1}$. We set $\psi_{H}$ to an arbitrarily small value in line with ruling out default in state $H$ and calibrate $\psi_{L}>\psi_{H}$ to attain a primary surplus of $\hat{T}_{L}-G=0.40$ (where $G=0$ without loss of generality). Expected output

$$
E[Y]=(1-\gamma) Y_{H}+\gamma Y_{L}
$$

is normalized to unity such that the primary surplus can be interpreted as $40 \%$ of expected GDP. The fixed and budgetary costs of default are calibrated to $\Phi=\alpha=0.10$ amounting to $10 \%$ of expected GDP each when $B_{0}=1$ (we consider different calibrations for $\Phi_{s}$ below). Given the two-period structure of our model, these figures are in terms of present discounted values. Finally, $q$ is set to 0.99 consistent with a risk-free interest rate of $1 \%$ and we also set $\gamma=0.10$ in line with the regularity conditions in Section 2.3.

Figure 4 depicts the equilibria without tranching $(\omega=0)$. Panel 1 shows the evolution of haircuts $\theta_{L}$ (on the y-axis) against the government's initial financing needs $B_{0}$ (on the 
Figure 4: Equilibria without tranching
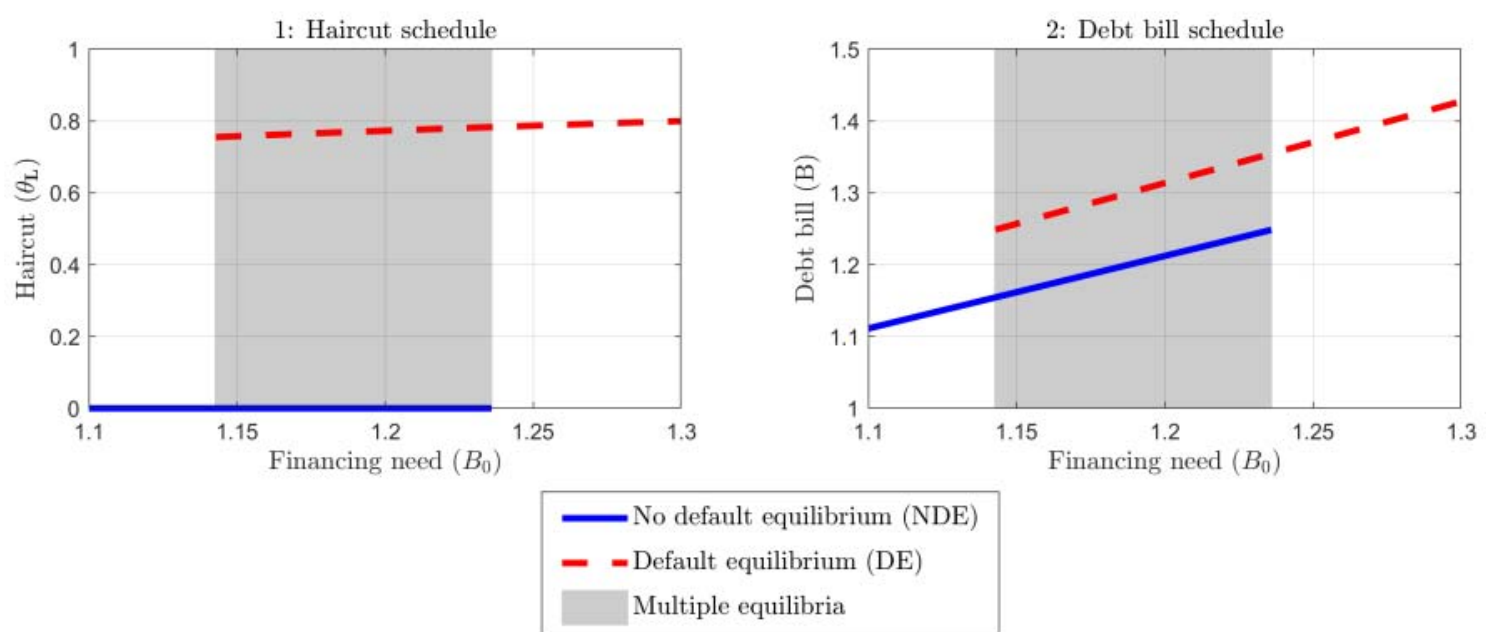

$\mathrm{x}$-axis). The shaded areas display the regions with multiple equilibria. Equilibrium regions are monotonic in $B_{0}$; from left to right, we have a unique $N D E$, multiplicity between $N D E$ and $D E$, and a unique $D E$.

Due to the fixed default costs $\Phi>0$, the haircut in state $L$ rises discretely to a minimum haircut $\underline{\theta}=0.76$ as the equilibrium switches from $N D E$ to $D E$. In the range of $B_{0}$ displayed, the haircut remains in the interior region and therefore continues to rise with $B_{0}$. Panel 2 shows that discrete changes in haircuts also cause jumps in the government's debt bill $B$. It also indicates that, under our calibration, sovereign spreads over the risk-free rate are around $10 \%$ in $D E$.

Figure 5 plots the relevant threshold values for the senior tranche size $\omega$ (on the y-axis) across $B_{0}$. In Panel 1, $\underline{\omega}$ depicts the minimum tranche size required to take the haircut to the upper corner. For $\omega<\underline{\omega}_{L}$, tranching is completely ineffective as per the Modigliani-Miller ineffectiveness result and only serves to re-allocate payments from the junior to the senior tranche. The schedule $\omega^{*}$ shows the minimum senior tranche size required to prevent default, thus ruling out $D E$.

Observe that as $B_{0}$ rises, $\underline{\omega}$ decreases while $\omega^{*}$ increases. Therefore, at high levels of $B_{0}$, smaller tranche sizes may have an effect while eliminating default require as very large senior tranche. Eliminating the bad equilibrium in multiplicity regions, however, only requires a senior tranche size of approximately $50 \%$. 
Figure 5: Tranching

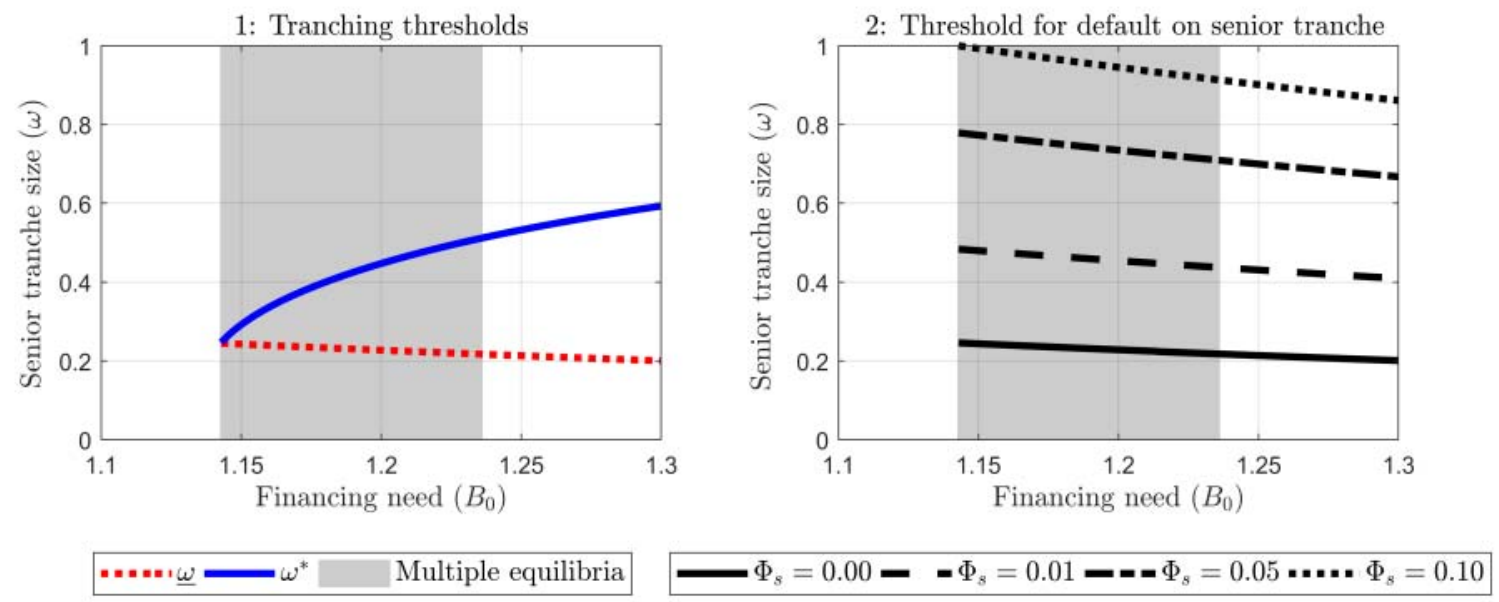

Finally, Panel 2 plots the threshold $\bar{\omega}$ above which there is default on the senior tranche at different levels of $\Phi_{s}$, the additional fixed default cost for doing so. At $\Phi_{s}=0$, there is no intermediate region between $\underline{\omega}$ and $\bar{\omega}$ where tranching may have an effect. We show that as $\Phi_{s}$ rises, however, $\bar{\omega}$ shifts up and senior tranche sizes may get large to prevent default at increasingly higher values of $B_{0}$.

\section{Conclusion}

We have analyzed the effects of tranching on sovereign risk in a standard model of debt crises with risk neutral creditors, costly default and a government that faces a trade-off between distortionary taxation and applying an (optimal) haircut to bondholders. Introducing tranching into the model yields two important insights. First, default costs on senior bonds may transpire into commitment to repay both the senior and junior tranches. Second, the effect of tranching on resilience to debt crises is highly non-linear in the senior tranche size.

We found that tranching only redistributes government revenues from junior to senior bondholders unless default costs are higher for senior than for junior bonds, and the senior tranche size is sufficiently but not too large. We characterize a lower and an upper threshold for this tranche that defines the region over which the seniority structure is not neutral.

Remarkably, in this intermediate region, tranching reduces vulnerability to debt crises. 
This is because, without any remaining funds to redistribute from the junior tranche, the government is forced to raise tax revenues to pay the senior tranche. This results in an increase in total payments to bondholders, which in turn leads to a fall in government borrowing costs given default expectations. Borrowing costs may then fall enough to eliminate the default equilibrium altogether.

We should stress in conclusion that our results can be applied more broadly. The mechanisms considered here are relevant for any situation in which there are fixed costs associated with default, and agents may take costly but non-contractible actions to increase recovery rates. Therefore, there may be a role for tranching corporate debt in sectors with significant moral hazard. 


\section{References}

Beck, T., Wagner, W., and Uhlig, H. (2011). Insulating the financial sector from the european debt crisis: Eurobonds without public guarantees. Short article at Voxeu.org. Attained from: https://voxeu.org/article/eurobonds-without-public-guarantees-insulatingfinancial-sector-european-debt-crisis.

Brunnermeier, M. K., Garicano, L., Lane, P. R., Pagano, M., Reis, R., Santos, T., Thesmar, D., Van Nieuwerburgh, S., and Vayanos, D. (2016). The sovereign-bank diabolic loop and esbies. American Economic Review, 106(5):508-12.

Brunnermeier, M. K., Langfield, S., Pagano, M., Reis, R., Van Nieuwerburgh, S., and Vayanos, D. (2017). ESBies: safety in the tranches. Economic Policy, 32(90):175-219.

Calvo, G. A. (1988). Servicing the public debt: The role of expectations. The American Economic Review, 78(4):647-661.

Cole, H. L. and Kehoe, T. J. (2000). Self-fulfilling debt crises. The Review of Economic Studies, 67(1):91-116.

Corsetti, G. and Dedola, L. (2016). The mystery of the printing press: Monetary policy and self-fulfilling debt crises. Journal of the European Economic Association, 14(6):1329-1371.

Delpla, J. and von Weizsäcker, J. (2010). The Blue Bond Proposal. Policy Briefs 403, Bruegel.

Eijffinger, S. C. (2011). Eurobonds-concepts and implications. Technical report, Briefing Note to the European Parliament.

European Commission (2011). Green paper on the feasibility of introducing stability bonds. Technical report.

German Council of Economic Experts (2012). After the euro area summit: Time to implement long-term solutions. Technical report.

Hatchondo, J. C., Martinez, L., and Onder, Y. K. (2017). Non-defaultable debt and sovereign risk. Journal of International Economics, 105(C):217-229. 
Lorenzoni, G. and Werning, I. (2013). Slow moving debt crises. Working Paper 19228, National Bureau of Economic Research.

Modigliani, F. and Miller, M. H. (1958). The cost of capital, corporation finance and the theory of investment. The American Economic Review, 48(3):261-297.

Muellbauer, J. (2011). Resolving the eurozone crisis: time for conditional eurobonds. CEPR Policy Insight, 59:12.

Nicolini, J. P., Teles, P., Ayres, J. L., and Navarro, G. (2015). Sovereign Default: The Role of Expectations. Working Papers 723, Federal Reserve Bank of Minneapolis.

Philippon, T. and Hellwig, C. (2011). Eurobills, not eurobonds. Short article at Voxeu.org. Attained from: https://voxeu.org/article/eurobills-not-euro-bonds. 


\section{Appendix}

\section{A Proofs of Propositions}

\section{A.1 Proof of Proposition 1}

No default equilibrium $(N D E)$ To begin with, consider an equilibrium with no default in any state such that $\theta^{N D E}=0$. Then the interest parity condition (10) indicates that

$$
\begin{aligned}
q_{b}^{N D E} & =q \\
B^{N D E} & =\frac{B_{0}}{q}
\end{aligned}
$$

and (4) gives us the following condition for the absence of default to be confirmed in equilibrium

$$
\hat{\theta}^{N D E}=\frac{1}{1-\alpha}-\frac{\hat{T}-G}{1-\alpha} \frac{q}{B^{N D E}}<\underline{\theta}
$$

We can re-arrange to write this in terms of government debt

$$
B^{N D E}<\frac{\hat{T}-G}{1-\underline{\theta}(1-\alpha)}
$$

which in terms of initial financing need becomes

$$
B_{0}<\frac{q(\hat{T}-G)}{1-\underline{\theta}(1-\alpha)}
$$

Using (3), a sufficient condition for $N D E$ to be self-confirming is

$$
B_{0}<\bar{B}_{0} \equiv \frac{q(\hat{T}-G)}{1-\underline{\theta}(1-\alpha)}
$$


Default equilibrium $(D E) \quad$ Now consider an equilibrium with default in state $L$ such that $\theta \in[\underline{\theta}, 1]$. In an interior solution $\theta=\hat{\theta} \in[\underline{\theta}, 1)$, we will have

$$
\begin{aligned}
\hat{\theta}^{D E} & =\frac{1}{1-\alpha}-\frac{\hat{T}-G}{(1-\alpha) B^{D E}} \\
q_{b}^{D E} & =q\left[1-\frac{\gamma}{1-\alpha}\left(1-\frac{\hat{T}-G}{B^{D E}}\right)\right]
\end{aligned}
$$

In terms of initial financing needs, the equilibrium is then characterized as

$$
\begin{aligned}
\hat{\theta}^{D E} & =\frac{B_{0}-(\hat{T}-G) q}{(1-\alpha) B_{0}-\gamma(\hat{T}-G) q} \\
q_{b}^{D E} & =\frac{(1-\alpha-\gamma) B_{0} q}{(1-\alpha) B_{0}-\gamma(\hat{T}-G) q} \\
B^{D E} & =\frac{(1-\alpha) \frac{B_{0}}{q}-\gamma(\hat{T}-G)}{1-\alpha-\gamma}
\end{aligned}
$$

There are three conditions for this interior equilibrium to exist:

$$
\begin{aligned}
& \hat{\theta}^{D E}>\underline{\theta} \leftrightarrow B^{D E}>\frac{\hat{T}-G}{1-(1-\alpha) \underline{\theta}} \\
& \hat{\theta}^{D E}<1 \leftrightarrow B^{D E}<\frac{\hat{T}-G}{\alpha}
\end{aligned}
$$

and in terms of financing needs, they become

$$
\begin{aligned}
& B_{0} \geq \underline{B}_{0} \equiv \frac{1-\gamma \underline{\theta}}{1-(1-\alpha) \underline{\theta}} q(\hat{T}-G) \\
& B_{0} \leq \frac{1-\gamma}{\alpha} q(\hat{T}-G)
\end{aligned}
$$

Secondly, there is a corner solution with $\theta^{D E+}=1$. In this equilibrium, government 
bonds are priced at

$$
\begin{aligned}
q_{b}^{D E+} & =q(1-\gamma) \\
B_{b}^{D E+} & =\frac{B_{0}}{q(1-\gamma)}
\end{aligned}
$$

and the equilibrium condition is

$$
\hat{\theta}^{D E+} \geq 1 \leftrightarrow B^{D E+} \geq \frac{\hat{T}-G}{\alpha}
$$

which in terms of financing needs become

$$
B_{0} \geq \frac{1-\gamma}{\alpha} q(\hat{T}-G)
$$

With continuity between interior and corner equilibria, the boundary above with $D E$ is self-confirming is given by

$$
\hat{\theta}^{D E} \geq \underline{\theta}
$$

or in terms of financing needs

$$
B_{0} \geq \underline{B}_{0}
$$

Coexistence of equilibria $N D E$ and $D E$ equilibria coexist when financing needs fall in the range

$$
\begin{gathered}
\underline{B}_{0} \leq B_{0}<\bar{B}_{0} \\
\therefore \frac{1-\gamma \underline{\theta}}{1-(1-\alpha) \underline{\theta}}(\hat{T}-G) \leq \frac{B_{0}}{q}<\frac{\hat{T}-G}{1-(1-\alpha) \underline{\theta}}
\end{gathered}
$$

This is non-empty under the condition

$$
\begin{gathered}
\frac{1-\gamma \underline{\theta}}{1-(1-\alpha) \underline{\theta}}(\hat{T}-G)<\frac{\hat{T}-G}{1-(1-\alpha) \underline{\theta}} \\
\therefore \underline{\theta}>0
\end{gathered}
$$


which will be satisfied when there is a strictly positive fixed cost of default $\Phi>0$.

\section{A.2 Proof of Proposition 2}

The solution for the interior case of $D E$ is provided in Appendix B. Using this solution, (32a) indicates that

$$
\frac{\partial B^{D E}}{\partial \omega}=0
$$

as long as $\omega$ remains at a level that does not lead to a corner solution $\theta^{D E}=1$. Using (31), we can also show that

$$
\begin{aligned}
\frac{\partial \theta^{D E}}{\partial \omega} & =\frac{1}{(1-\alpha)(1-\omega)^{2}}\left(1-\frac{\hat{T}-G}{B}\right) \\
& =\frac{\theta^{D E}}{1-\omega}>0
\end{aligned}
$$

To determine how $\omega$ affects the minimum haircut, let

$$
\begin{aligned}
f(\omega, \theta) \equiv & z\left(\hat{T}+\frac{(1-\omega)(1-\alpha) \theta}{\omega+(1-\omega)(1-(1-\alpha) \theta)}(\hat{T}-G)\right)-z\left(\hat{T}_{i}\right)-\Phi \\
& -\frac{\alpha(1-\omega) \theta}{\omega+(1-\omega)(1-(1-\alpha) \theta)}(\hat{T}-G)
\end{aligned}
$$

such that $(20)$ indicates $f(\omega, \underline{\theta})=0$. Since $\hat{T}$ is independent of $\omega$ and

$$
\frac{\partial\left(\frac{(1-\omega) \theta}{\omega+(1-\omega)(1-(1-\alpha) \theta)}\right)}{\partial \omega}=\frac{-\theta}{[\omega+(1-\omega)(1-(1-\alpha) \theta)]^{2}}<0
$$

we can show that

$\frac{\partial f(\omega, \theta)}{\partial \omega}=\frac{\theta_{i}(\hat{T}-G)(1-\alpha)}{[\omega+(1-\omega)(1-(1-\alpha) \theta)]^{2}}\left[\frac{\alpha}{1-\alpha}-z^{\prime}\left(\hat{T}+\frac{(1-\omega)(1-\alpha) \theta}{\omega+(1-\omega)(1-(1-\alpha) \theta)}(\hat{T}-G)\right)\right]$

This is negative under the condition

$$
\frac{\alpha}{1-\alpha}<z^{\prime}\left(\hat{T}+\frac{(1-\omega)(1-\alpha) \theta}{\omega+(1-\omega)(1-(1-\alpha) \theta)}(\hat{T}-G)\right)
$$


which must be satisfied since $z^{\prime}(\hat{T})=\frac{\alpha}{1-\alpha}$ by virtue of the interior FOC and $z^{\prime \prime}()>$.0 .

Moreover, using (28), we can also write

$$
\begin{aligned}
\frac{\partial f(\omega, \theta)}{\partial \theta} & =\frac{(1-\omega)(1-\alpha)(\hat{T}-G)}{[\omega+(1-\omega)(1-(1-\alpha) \theta)]^{2}}\left[z_{i}^{\prime}\left(\hat{T}+\frac{(1-\omega)(1-\alpha) \theta}{\omega+(1-\omega)(1-(1-\alpha) \theta)}(\hat{T}-G)\right)-\frac{\alpha}{1-\alpha}\right] \\
& >0
\end{aligned}
$$

Through the implicit function theorem, we can deduce that

$$
\begin{gathered}
\frac{\partial f(\omega, \underline{\theta})}{\partial \omega}+\frac{\partial \underline{\theta}}{\partial \omega} \frac{\partial f(\omega, \underline{\theta})}{\partial \underline{\theta}}=0 \\
\therefore \frac{\partial \underline{\theta}}{\partial \omega}=-\frac{\frac{\partial f(\omega, \underline{\theta})}{\partial \omega}}{\frac{\partial f(\omega, \underline{\theta})}{\partial \hat{\theta}}}=\frac{\underline{\theta}}{1-\omega}>0
\end{gathered}
$$

for all $(\omega, \underline{\theta})$ within the unit circle. Using $(29)$, we can then write

$$
\frac{\partial \hat{\theta}}{\partial \omega}>\frac{\partial \underline{\theta}}{\partial \omega} \forall \hat{\theta}>\underline{\theta}
$$

Finally, to show that the boundaries $\left(\underline{B}_{0}, \bar{B}_{0}\right)$ are independent of $\omega$, let

$$
g(\omega, B) \equiv z(G+B)-z(T)-\Phi-\alpha(1-\omega) \theta B
$$

where (18) indicates that $g(\omega, B)=0$ at a boundary. This yields the derivatives

$$
\begin{aligned}
\frac{\partial g(\omega, B)}{\partial \omega} & =\frac{\partial B}{\partial \omega} z^{\prime}(G+B)-\frac{\partial T_{i}}{\partial \omega} z^{\prime}(T)-\alpha \frac{\partial((1-\omega) \theta B)}{\partial \omega} \\
\frac{\partial g(\omega, B)}{\partial B} & =z^{\prime}(G+B)-\frac{\partial T}{\partial B} z^{\prime}(T)-\alpha \frac{\partial((1-\omega) \theta B)}{\partial B}
\end{aligned}
$$


In an interior solution, we know that

$$
\begin{gathered}
\frac{\partial B}{\partial \omega}=0 \\
\frac{\partial T}{\partial \omega}=\frac{\partial T}{\partial B}=0 \\
\frac{\partial((1-\omega) \theta B)}{\partial \omega}=0 \\
\frac{\partial((1-\omega) \theta B)}{\partial B}=\frac{1}{1-\alpha}
\end{gathered}
$$

Combining these with the derivatives above indicates

$$
\begin{aligned}
& \frac{\partial g(\omega, B)}{\partial \omega}=0 \\
& \frac{\partial g(\omega, B)}{\partial B}=z^{\prime}(G+B)-\frac{\alpha}{1-a}>0
\end{aligned}
$$

and by the implicit function theorem we have that, on a boundary $\left(\underline{B}_{0}, \bar{B}^{0}\right)$

$$
\frac{\partial B}{\partial \omega}=-\frac{\frac{\partial f(\omega, B)}{B}}{\frac{\partial f(\omega, B)}{\omega}}=0
$$

Since, $B$ is a positive function of $B_{0}$ and independent of $\omega$ in an interior solution, we can further write

$$
\frac{\partial \underline{B}_{0}}{\partial \omega}=\frac{\partial \bar{B}_{0}}{\partial \omega}=0
$$

In other words, $\omega$ has no effect on the equilibrium boundaries when the haircut falls short of an upper corner $\theta^{D E}=1$.

\section{A.3 Proof of Proposition 3}

$B^{D E}$ is given by (33) and combining this with the corner default condition (21) yields the implicit expression (23) for $\omega^{*}$. It follows from Proposition 1 that $\omega^{*}>\underline{\omega}$. To show that $\omega^{*}<1$, we simply set $\omega=1$ in the default condition (21). In this case, not defaulting is leads to strictly higher welfare for any fixed default cost

$$
\Phi>0
$$


which shows that $\omega^{*}<1$ since reducing the size of the senior tranche by an arbitrarily small amount would still lead to no default.

Finally, to show that $\omega^{*}$ is increasing in $B_{0}$, let

$$
\begin{aligned}
f\left(\omega, B_{0}\right) \equiv & z\left(G+\frac{B_{0}}{q(1-\gamma(1-\omega))}\right)-z\left(G+\frac{\omega+(1-\omega) \alpha}{1-\gamma(1-\omega)} \frac{B_{0}}{q}\right) \\
& -\Phi-\frac{\alpha(1-\omega)}{1-\gamma(1-\omega)} \frac{B_{0}}{q}
\end{aligned}
$$

such that $f\left(\omega^{*}, B_{0}\right)=0$. This leads to the derivatives

$$
\begin{aligned}
\frac{\partial f(\omega, D)}{\partial \omega} & =\frac{\frac{B_{0}}{q}\left[\alpha-\gamma z^{\prime}\left(G+\frac{1}{1-\gamma(1-\omega)} \frac{B_{0}}{q}\right)-(1-\alpha-\gamma) z^{\prime}\left(G+\frac{\omega+(1-\omega) \alpha}{1-\gamma(1-\omega)} \frac{B_{0}}{q}\right)\right]}{(1-\gamma(1-\omega))^{2}}, \\
\frac{\partial f(\omega, D)}{\partial B_{0}} & =\frac{z^{\prime}\left(G+\frac{1}{1-\gamma(1-\omega)} \frac{B_{0}}{q}\right)-(\omega+(1-\omega) \alpha) z^{\prime}\left(G+\frac{\omega+(1-\omega) \alpha}{1-\gamma(1-\omega)} \frac{B_{0}}{q}\right)-\alpha(1-\omega)}{q(1-\gamma(1-\omega))}
\end{aligned}
$$

Since $\alpha<1$, a sufficient condition for $\frac{\partial f(\omega, D)}{\partial \omega}<0$ and $\frac{\partial f(\omega, D)}{\partial B_{0}}>0$ is

$$
z^{\prime}\left(G+\frac{\omega+(1-\omega) \alpha}{1-\gamma(1-\omega)} \frac{B_{0}}{q}\right)>\frac{\alpha}{1-\alpha}
$$

which must be true since

$$
z^{\prime}\left(G+\frac{\omega+(1-\omega) \alpha}{1-\gamma(1-\omega)} \frac{B_{0}}{q}\right)>z(\hat{T})=\frac{\alpha}{1-\alpha}
$$

Therefore, using the implicit function theorem and $f\left(\omega^{*}, B_{0}\right)=0$, we can write

$$
\frac{\partial \omega^{*}}{\partial B_{0}}=-\frac{\frac{\partial f(\omega, D)}{\partial B_{0}}}{\frac{\partial f(\omega, D)}{\partial \omega}}>0
$$




\section{A.4 Proof of Proposition 4}

To begin with, consider the interior equilibrium. Combining (24) with (25) yields

$$
\begin{aligned}
B^{S D E} & =\frac{(1-\alpha) \frac{B_{0}}{q}-\gamma(\hat{T}-G)}{1-\alpha-\gamma} \\
\theta_{s}^{S D E} & =\frac{1}{\omega} \frac{(\omega+\alpha(1-\omega)) \frac{B_{0}}{q}-(1-\gamma(1-\omega))(\hat{T}-G)}{(1-\alpha) \frac{B_{0}}{q}-\gamma(\hat{T}-G)}
\end{aligned}
$$

where taxes $\hat{T}$ are pinned down by (5). The interior equilibrium is valid under the condition

$$
\frac{B_{0}}{q}>\frac{1-\gamma}{\alpha}(\hat{T}-G)
$$

Otherwise, the equilibrium is at the corner $\theta_{s}^{S D E}=1$ with debt and taxes given by

$$
\begin{aligned}
B^{S D E} & =\frac{B_{0}}{q(1-\gamma)} \\
T^{S D E} & =G+\alpha B^{S D E}
\end{aligned}
$$

The default condition can be written as

$$
z\left(G+(\omega+(1-\omega) \alpha) B^{S D E}\right)>z\left(T^{S D E}\right)+\Phi_{s}+\omega \alpha \theta_{s}^{S D E} B^{S D E}
$$

which in an interior equilibrium becomes

$$
z\left(\hat{T}+(1-\alpha) x\left(\omega, B_{0}\right)\right)>z(\hat{T})+\Phi_{s}+\alpha x\left(\omega, B_{0}\right)
$$

where

$$
x\left(\omega, B_{0}\right) \equiv \frac{(\omega+(1-\omega) \alpha) \frac{B_{0}}{q}-(1-\gamma(1-\omega))(\hat{T}-G)}{1-\alpha-\gamma}
$$

To analyze the properties of $\bar{\omega}$ let

$$
f\left(B_{0}, \Phi_{s}, \omega\right) \equiv z\left(\hat{T}+(1-\alpha) x\left(\omega, B_{0}\right)\right)-\Phi_{s}-z(\hat{T})-\alpha x\left(\omega, B_{0}\right)
$$


such that $f\left(B_{0}, \Phi_{s}, \bar{\omega}\right)=0$. We can then write the derivatives

$$
\begin{aligned}
& \frac{\partial f\left(\omega, B_{0}\right)}{\partial \omega}=(1-\alpha) z^{\prime}\left(\hat{T}+(1-\alpha) x\left(\omega, B_{0}\right)\right) \frac{\partial x\left(\omega, B_{0}\right)}{\partial \omega}-\alpha \frac{\partial x\left(\omega, B_{0}\right)}{\partial \omega} \\
& \frac{\partial f\left(\omega, B_{0}\right)}{\partial B_{0}}=(1-\alpha) z^{\prime}\left(\hat{T}+(1-\alpha) x\left(\omega, B_{0}\right)\right) \frac{\partial x\left(\omega, B_{0}\right)}{\partial B_{0}}-\alpha \frac{\partial x\left(\omega, B_{0}\right)}{\partial B_{0}} \\
& \frac{\partial f\left(\omega, B_{0}\right)}{\partial \Phi_{s}}=-1<0
\end{aligned}
$$

Using

$$
\begin{aligned}
\frac{\partial x\left(\omega, B_{0}\right)}{\partial \omega} & =\frac{\left((1-\alpha) \frac{B_{0}}{q}-\gamma(\hat{T}-G)\right) x\left(\omega, B_{0}\right)}{(\omega+(1-\omega) \alpha) \frac{B_{0}}{q}-(1-\gamma(1-\omega))(\hat{T}-G)} \\
\frac{\partial x\left(\omega, B_{0}\right)}{\partial B_{0}} & =\frac{\omega+(1-\omega) \alpha}{1-\alpha-\gamma}
\end{aligned}
$$

it is straightforward to show that we will have

$$
\frac{\partial x\left(\omega, B_{0}\right)}{\partial \omega}>0, \frac{\partial x\left(\omega, B_{0}\right)}{\partial B_{0}}>0
$$

under the regularity condition $1-\gamma>\alpha$. The derivatives of $f\left(\omega, B_{0}\right)$ with respect to $\left(\omega, B_{0}\right)$ will then also be positive under the condition

$$
z^{\prime}\left(\hat{T}+(1-\alpha) x\left(\omega, B_{0}\right)\right)>\frac{\alpha}{1-\alpha}
$$

which must be true since

$$
z^{\prime}(\hat{T})=\frac{\alpha}{1-\alpha}, z^{\prime \prime}(.)>0
$$

Using the implicit function theorem, we can then write

$$
\begin{aligned}
\frac{\partial \bar{\omega}}{\partial \Phi_{s}}>0 \\
\frac{\partial \bar{\omega}}{\partial B_{0}}<0
\end{aligned}
$$


Note also that using (30) and (22), we can also show that

$$
f\left(B_{0}, \Phi_{s}, \underline{\omega}\right)=-\Phi_{s}
$$

which indicates that we will have $\bar{\omega}>\underline{\omega}$ for any $\Phi_{s}>0$.

Finally, we conduct the same analysis for the corner solution, in which case the default condition is

$$
\begin{aligned}
z\left(G+\frac{\omega+(1-\omega) \alpha}{1-\gamma} \frac{B_{0}}{q}\right)> & z\left(G+\frac{\alpha}{1-\gamma} \frac{B_{0}}{q}\right)+\Phi_{s} \\
& +\frac{\omega \alpha}{1-\gamma} \frac{B_{0}}{q}
\end{aligned}
$$

We can then write

$$
\begin{aligned}
f\left(B_{0}, \Phi_{s}, \omega\right) \equiv & z\left(G+\frac{\omega+(1-\omega) \alpha}{1-\gamma} \frac{B_{0}}{q}\right)-\Phi_{s}-\frac{\omega \alpha}{1-\gamma} \frac{B_{0}}{q} \\
& -z\left(G+\frac{\alpha}{1-\gamma} \frac{B_{0}}{q}\right)
\end{aligned}
$$

such that $f\left(B_{0}, \Phi_{s}, \bar{\omega}\right)=0$ and

$$
\begin{aligned}
& \frac{\partial f\left(\omega, B_{0}\right)}{\partial \omega}=\left((1-\alpha) z^{\prime}\left(G+\frac{\omega+(1-\omega) \alpha}{1-\gamma} \frac{B_{0}}{q}\right)-\alpha\right) \frac{B_{0}}{(1-\gamma) q}>0 \\
& \frac{\partial f\left(\omega, B_{0}\right)}{\partial B_{0}}=\left(\begin{array}{c}
(\omega+(1-\omega) \alpha) z^{\prime}\left(G+\frac{\omega+(1-\omega) \alpha}{1-\gamma} \frac{B_{0}}{q}\right)-\omega \alpha \\
-\alpha z^{\prime}\left(G+\frac{\alpha}{1-\gamma} \frac{B_{0}}{q}\right)
\end{array}\right) \frac{1}{(1-\gamma) q}>0 \\
& \frac{\partial f\left(\omega, B_{0}\right)}{\partial \Phi_{s}}=-1<0
\end{aligned}
$$

As with the interior case, under the implicit function theorem this implies

$$
\begin{aligned}
\frac{\partial \bar{\omega}}{\partial \Phi_{s}} & >0 \\
\frac{\partial \bar{\omega}}{\partial B_{0}} & <0
\end{aligned}
$$


Moreover, we can write $\bar{\omega}>\underline{\omega}$ for all $\Phi_{s}>0$ since

$$
f\left(B_{0}, \Phi_{s}, \underline{\omega}\right)=-\Phi_{s}
$$

where $\underline{\omega}=0$ must be true since we are at the corner equilibrium already at the boundary where $S D E$ becomes self-confirming.

\section{B Equilibria under tranching}

\section{No default equilibrium $(N D E)$}

Tranching does not change anything in the no default equilibrium as both senior and junior bonds are repaid fully. The equilibrium is characterized by

$$
\begin{aligned}
\theta & =0 \\
q_{b}^{N D E} & =q \\
B^{N D E} & =\frac{B_{0}}{q} \\
T^{N D E} & =G+\frac{B_{0}}{q}
\end{aligned}
$$

but the condition for this equilibrium to be self-confirming depends on $\omega$. It follows from Proposition 2 that senior tranches below the size

$$
\omega \leq \underline{\omega}^{N D E} \equiv \frac{1}{1-\alpha}\left(\frac{\hat{T}-G}{B_{0} / q}-\alpha\right)
$$

leave the condition to confirm the equilibrium identical to the case without tranching de-

scribed in Proposition 1. For $\omega \leq \underline{\omega}^{N D E}$, any deviation to default is at a corner solution and the relevant condition to confirm $N D E$ is $B_{0} \leq \bar{B}_{0}(\omega)$ where $\bar{B}_{0}$ is implicitly defined as a function of $\omega$ by the expression

$$
z\left(G+\frac{\bar{B}_{0}}{q}\right)=z\left(G+(\omega+(1-\omega) \alpha) \frac{\bar{B}_{0}}{q}\right)+\Phi+\alpha(1-\omega) \frac{\bar{B}_{0}}{q}
$$


such that

$$
\frac{\partial \bar{B}_{0}}{\partial \omega}>0 \forall \omega \in\left(\underline{\omega}^{N D E}, 1\right)
$$

\section{Default equilibrium $(D E)$}

We begin with the interior case, where $D E$ is characterized by the set of expressions

$$
\begin{aligned}
\theta^{D E} & =\hat{\theta}^{D E}=\frac{1}{(1-\alpha)(1-\omega)}\left(1-\frac{\hat{T}-G}{B^{D E}}\right) \\
q_{b}^{D E} & =q\left[1-\frac{\gamma}{(1-\alpha)(1-\omega)}\left(1-\frac{\hat{T}-G}{B^{D E}}\right)\right] \\
B^{D E} & =\frac{B_{0}}{\omega q+(1-\omega) q_{b}^{D E}} \\
T^{D E} & =\hat{T}
\end{aligned}
$$

which in terms of initial financing needs become

$$
\begin{aligned}
\hat{\theta}^{D E} & =\frac{1}{1-\omega} \frac{\frac{B_{0}}{q}-(\hat{T}-G)}{(1-\alpha) \frac{B_{0}}{q}-\gamma(\hat{T}-G)} \\
q_{b}^{D E} & =\frac{q}{1-\omega} \frac{((1-\alpha)(1-\omega)-\gamma) \frac{B_{0}}{q}+\gamma \omega(\hat{T}-G)}{(1-\alpha) \frac{B_{0}}{q}-\gamma(\hat{T}-G)} \\
T^{D E} & =\hat{T}
\end{aligned}
$$

Observe that tax revenues in the defaulting state are not affected by $\omega$. Instead, the government increases the haircuts on junior bonds to fully pay the senior tranche and junior bond prices $q_{b}^{D E}$ decline in anticipation of a higher haircut. Under risk neutrality, the decline in $q_{b}^{D E}$ exactly offsets the higher prices for the senior tranche such that the government's total debt bill remains unchanged compared to the case without tranching

$$
B^{D E}=\frac{B_{0}}{\omega q+(1-\omega) q_{b}^{D E}}=\frac{(1-\alpha) \frac{B_{0}}{q}-\gamma(\hat{T}-G)}{1-\alpha-\gamma}
$$


This interior case is valid when the size of the senior tranche remains below

$$
\omega \leq \underline{\omega} \equiv \frac{(1-\gamma)(\hat{T}-G)-\alpha \frac{B_{0}}{q}}{(1-\alpha) \frac{B_{0}}{q}-\gamma(\hat{T}-G)}
$$

In this case, the condition for $D E$ to be self-confirming remains identical to the case without tranching described in Proposition 1

When $\omega>\underline{\omega}$, on the other hand, $D E$ is characterized by the (upper) corner case such that

$$
\begin{aligned}
\theta^{D E+} & =1 \\
q_{b}^{D E+} & =q(1-\gamma) \\
B^{D E+} & =\frac{B_{0}}{\omega q+(1-\omega) q_{b}^{D E+}} \\
T^{D E+} & =G+\frac{\omega+(1-\omega) \alpha}{1-\gamma(1-\omega)} \frac{B_{0}}{q}
\end{aligned}
$$

Since the government is unable to increase the haircut on junior bonds further, a rise in $\omega$ leads to a rise in tax revenues collected during default. Moreover, as the junior bond prices remain fixed at $q_{b}^{D E+}<q_{b}$ in the corner solution, further increases in $\omega$ reduce the government's borrowing costs. Therefore, the debt bill $B^{D E+}$ decreases in $\omega$ as per the expression

$$
B^{D E+}=\frac{B_{0}}{q}[1-\gamma(1-\omega)]^{-1}
$$

Finally, $D E$ is self-confirming in the range of financing need $B_{0} \leq \underline{B}_{0}$ where $\underline{B}_{0}$ is implicitly by the expression

$$
\begin{aligned}
z\left(G+\frac{1}{1-\gamma(1-\omega)} \frac{\underline{B}_{0}}{q}\right)= & z\left(G+\frac{\omega+(1-\omega) \alpha}{1-\gamma(1-\omega)} \frac{\underline{B}_{0}}{q}\right) \\
& +\Phi+\frac{\alpha(1-\omega)}{1-\gamma(1-\omega)} \frac{\underline{B}_{0}}{q}
\end{aligned}
$$

such that

$$
\frac{\partial \underline{B}_{0}}{\partial \omega}>0 \forall \omega \in(\underline{\omega}, 1)
$$


Note that we can equivalently let (34) define a minimum senior tranche $\omega^{*}$ that eliminates $D E$. In this case, $\omega^{*}>\underline{\omega}$ would be increasing in $B_{0}$ but remain strictly below 1 at any given $B_{0}$. 